\title{
Use of Photochemical Transformations as a Route to Novel Molecular Scaffolds
}

\section{Carlos Tabarez, ${ }^{1}$ Shubhashis Chakrabarty, ${ }^{2}$ Jaime Franco, ${ }^{1}$ Michael Croft, ${ }^{2}$ Hui Yan Cheng, ${ }^{2}$ Brady Walter, ${ }^{2}$ Alex Khrizman, ${ }^{2}$ Patrick Moyna, ${ }^{1}$ and Guillermo Moyna ${ }^{1,2,3, *}$}

${ }^{1}$ Departamento de Tecnología Química, Facultad de Química, Universidad de la República, Montevideo 11800, Uruguay, ${ }^{2}$ Department of Chemistry \& Biochemistry, University of the Sciences, Philadelphia, PA 19104, USA, and ${ }^{3}$ Departamento de Química, Polo Agroalimentario y Agroindusgtrial del Litoral Oeste, Universidad de la República, Paysandu 60000, Uruguay.

*e-mail corresponding author: gmoyna@fq.edu.uy

Keywords: Cyclopropanes; Fluorenones; Indenoquinolines; Photoisomerization.

\section{INTRODUCTION}

Despite recent advances in medicine such as gene and targeted therapies, chemotherapy is still the first line of defense in the treatment of disease. Therefore, the search for novel bioactive compounds, either synthetic or natural, continues to be a critical area of research. Among the apporaches used for this purpose, the development of simple routes to expand the molecular diversity of known classes of compounds is common. While this usually involves derivatizations of a particular lead, methods that result in novel molecular scaffolds are particularly attractive. Examples of the latter are described in this presentation.

\section{RESULTS AND DISCUSSION}

We discuss the preparation of compounds ranging form tetracyclic indenoquinolines to subsituted cyclopropanes using photochemical transformations (Figure 1). The substrates used for this purpose have been investigated by our groups as potential antiparasitic agents. ${ }^{1,2}$ The compounds are a series of Diels-Alder adducts formed between benzotropolones or tropolones with suitable dienophiles, and which bear a common $\beta, \gamma$-unsaturated ketone chromophore. As detailed herein, the phototransformations are initiated by the formation of stable allyl or allyl/aroyl radicals. The oucome of the reaction depends on the nature of the substituents present in the substrate. ${ }^{3,4}$

\section{CONCLUSION}

The preparation of novel compounds from benzotropolone and tropolone derivatives by means of photachemical transformations will be presented. The biological activity, potential mode of action, and further derivatizations of some of these will also be discussed.

\section{ACKNOWLEDGEMENTS}

Financial support from ANII, CSIC, Merck/AAAS USRP, NSF, and RSC is acknowledged.

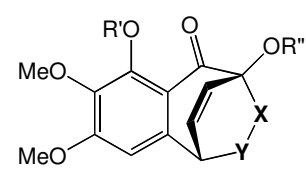

$\mathbf{X}=\mathrm{O} ; \mathbf{Y}=\mathrm{N}-\mathrm{Ph}$

$\mathbf{X}=\mathbf{Y}=\mathrm{N}-\mathrm{CO}_{2} \mathrm{R}^{\prime \prime}$ $\mathbf{X}-\mathbf{Y}=\mathrm{CH}-(\mathrm{C}=\mathrm{O})-\mathrm{O}-(\mathrm{C}=\mathrm{O})-\mathrm{CH}$
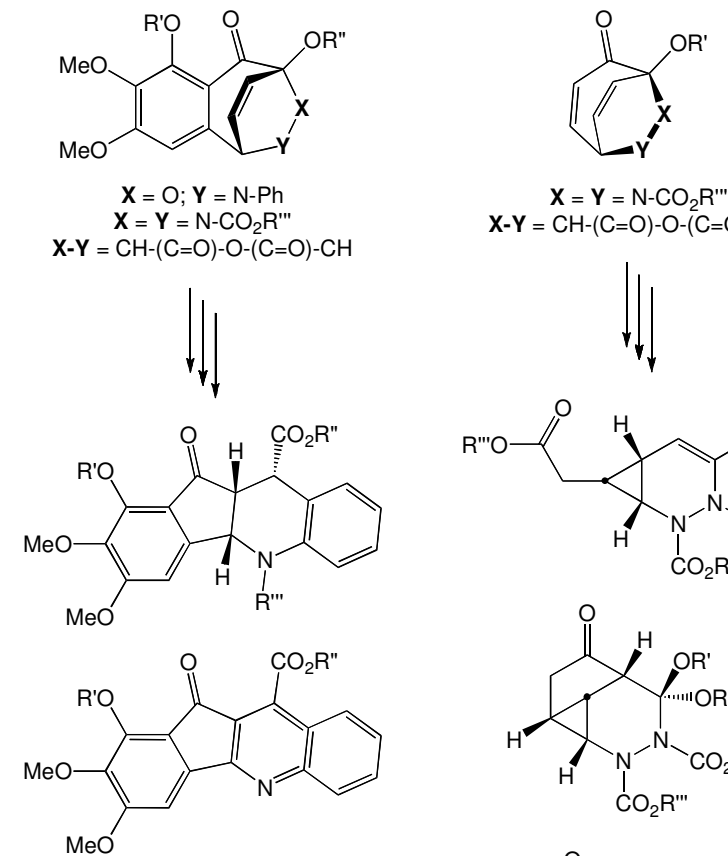

$\mathbf{X}=\mathbf{Y}=\mathrm{N}-\mathrm{CO}_{2} \mathrm{R}^{\prime \prime}$ $\mathbf{X}-\mathbf{Y}=\mathrm{CH}-(\mathrm{C}=\mathrm{O})-\mathrm{O}-(\mathrm{C}=\mathrm{O})-\mathrm{CH}$

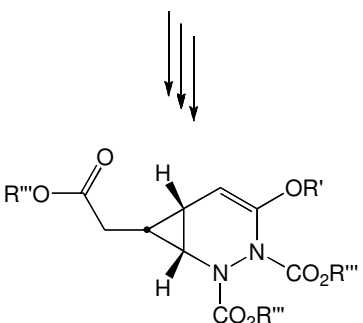
$\mathrm{CO}_{2} \mathrm{R}^{\prime \prime}$
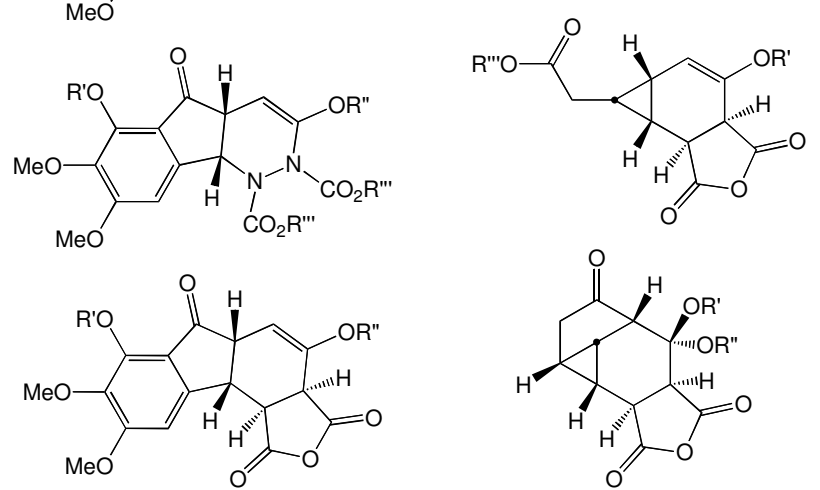

Figure 1. Photochemical transformation products of benzotropolone and tropolone derivatives.

\section{REFERENCES}

1) Khrizman, A.; Moulthrop, J. S.; Little, S.; Wharton, H.; Yardley, V.; Moyna, G. Bioorg. Med. Chem. Lett. 2007, 17, 4183-4186.

2) Khrizman, A.; Slack, R. D.; Remsing, R. C.; Little, S.; Yardley, V.; Moyna, G. Arch. Pharm. 2007, 340, 569-576.

3) Tabarez, C.; Waterman, C.; Rapp, A. L.; Moyna, P.; Moyna, G. Tetrahedron Lett. 2009, 50, 7128-7131.

4) Walter, B. L.; Tabarez, C.; Chang, H. Y.; Moyna, P.; Moyna, G. Synth. Commun. 2011 (in press). 